\title{
Numerical Solution for Reliability and Availability Analysis of a Three Unit Standby System
}

\author{
M. K. Sharma \\ Department of Mathematics, R.S.S. (PG), Pilkhuwa, (Hapur) \\ drmukeshsharma@gmail.com \\ Dr.Kapil Kumar Bansal \\ Head, Research \& Publication, SRM University, NCR Campus, Ghaziabad \\ drkapilbansal25@gmail.com
}

\begin{abstract}
This paper presents the stochastic model of a three unit redundant system having two types of failures. Besides the old technique for reliability analysis such as Laplace Transform Technique, Regenerative point technique, Boolean Function Technique, we have used the numerical method for reliability analysis for our self generated three unit standby system. In this present research paper we have used Euler's modified method. This method has been used to solve the differential-difference equations representing the system to obtain all state probabilities and the availability of the system.
\end{abstract}

American Math.Society (1991) Subject classification:- 90B25

Keywords: Reliability Modeling, System Availability, Euler's modified method and Stochastic Process.

\section{Introduction:-}

Reliability modeling of standby systems requires involvement of several states to represent a true picture of the functioning of the system. Further in the mathematical modeling of such systems, one gets system of differential-difference equations with the number of equations equaling the number of involved states. With large number of states and hence equations, the Laplace Transform (LT) technique for solving system of differential equations becomes tedious. Under the circumstances researchers usually make a compromise at the modeling stage by sacrificing some significant constraints to reduce the number of states and avoid complexities of LT technique with large number of equations. Sur \& Sarkar (3) used a numerical method to solve the system of differential-difference equations and demonstrated that the approximate results obtained by numerical method match considerably with the results obtained by LT technique. Present work studies the stochastic behaviour of a three unit standby system having two standby units and two types of failure modes.

Using Euler's modified method to solve the system of differential-difference equations representing the system, we have obtained the system state probabilities for success and failure states along with the computation of availability of the system.

The system state transition diagram is given in fig. 1. System under consideration consists of three units out of which one operates and the other two work as standbys, one warm and the other cold standby. 


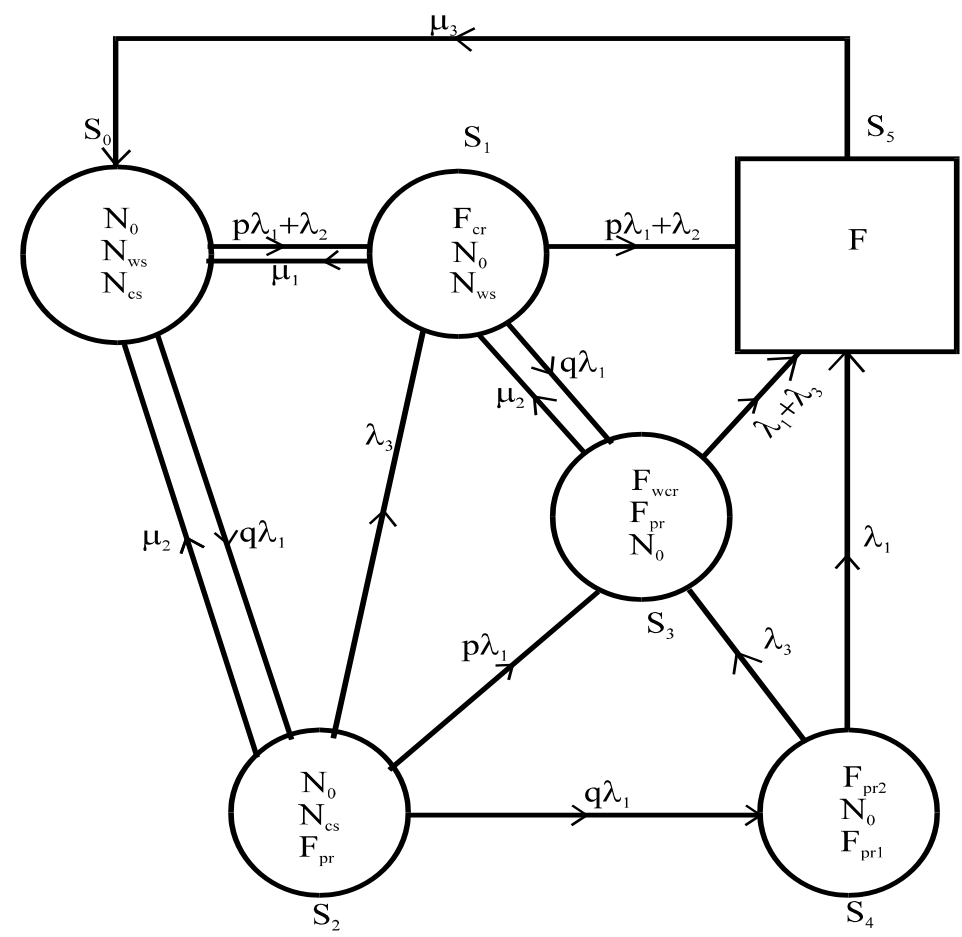

Figure-1

State $S_{0}$ represents the state where all units are in perfect condition. If the operative unit suffers a complete failure or the warm standby fails in standby mode, it transits to state S1, where the other unit takes over as operative unit and failed unit goes for repair. If the operative unit suffers a partial failure, then it transits to state $\mathrm{S}_{2}$. Upon the complete failure of operative unit or failure of warm standby in state $\mathrm{S}_{1}$, system arrives in completely failed state $S_{5}$. If in state $S_{1}$ the operative unit fails partially, the system transits to state $S_{3}$. This state is also arrived from state $S_{2}$ with the complete failure of operative unit. However the partial failure of the operative unit in state $S_{2}$ leads to state $S_{4}$. A partially failed unit may fail completely and under this situation system transits from $S_{4}$ to $S_{3}$ and $S_{3}$ to $S_{5}$. From states $S_{3}$ and $S_{4}$, the system is led to completely failed state $S_{5}$, if the operative unit fails in either mode. The system is assumed to be repairable with repairs taken to be as good as new.

\section{Assumptions:-}

1. An operative unit may fail completely or partially.

2. At least two units in working condition must be available to the system for its functioning.

3. Partially failed unit may work as warm standby.

4. Failure of warm standby in standby mode is always a complete failure.

5. A partially failed unit is repaired in priority to completely failed unit.

\section{Notations:-}

$\mathrm{P}_{\mathrm{i}}(\mathrm{t})=$ Probability that at any time $\mathrm{t}$ the system is in state $\mathrm{i}[\mathrm{i}=0,1,3,4]$.

$\lambda_{1}=$ Constant complete failure rate.

$\lambda_{2}=$ Complete failure rate in standby mode.

$\lambda_{3}=$ Failure rate from partial to complete failure.

$\mu_{1} \quad=\quad$ Constant repair rate from complete failure

$\mu_{2}=$ Constant repair rate from partial failure.

$\mu_{3} \quad=\quad$ Constant repair rate from failed state.

$\mathrm{p}=$ probability that the failure is complete.

$\mathrm{q}=$ probability that the failure is partial. 


\section{Mathematical formulation of the model:-}

The differential difference equations governing the system transition are: -

$$
\begin{aligned}
& \mathrm{P}_{0}^{\prime}(\mathrm{t})=-\left(\lambda_{1}+\lambda_{2}\right) \mathrm{P}_{0}(\mathrm{t})+\mu_{1} \mathrm{P}_{1}(\mathrm{t})+\mu_{2} \mathrm{P}_{2}(\mathrm{t})+\mu_{3} \mathrm{P}_{5}(\mathrm{t}) \\
& \mathrm{P}_{1}^{\prime}(\mathrm{t})=\left(\mathrm{p} \lambda_{1}+\lambda_{2}\right) \mathrm{P}_{0}(\mathrm{t})-\left(\lambda_{1}+\lambda_{2}+\mu_{1}\right) \mathrm{P}_{1}(\mathrm{t})+\lambda_{3} \mathrm{P}_{2}(\mathrm{t})+\mu_{2} \mathrm{P}_{3}(\mathrm{t}) \\
& \mathrm{P}_{2}^{\prime}(\mathrm{t})=\mathrm{q} \lambda_{1} \mathrm{P}_{0}(\mathrm{t})-\left(\lambda_{1}+\lambda_{3}+\mu_{2}\right) \mathrm{P}_{2}(\mathrm{t}) \\
& \mathrm{P}_{3}^{\prime}(\mathrm{t})=\mathrm{q} \lambda_{1} \mathrm{P}_{1}(\mathrm{t})+\mathrm{p} \lambda_{1} \mathrm{P}_{2}(\mathrm{t})-\left(\lambda_{1}+\lambda_{3}+\mu_{2}\right) \mathrm{P}_{3}(\mathrm{t})+\lambda_{3} \mathrm{P}_{4}(\mathrm{t}) \\
& \mathrm{P}_{4}^{\prime}(\mathrm{t})=\mathrm{q} \lambda_{1} \mathrm{P}_{2}(\mathrm{t})-\left(\lambda_{1}+\lambda_{3}\right) \mathrm{P}_{4}(\mathrm{t}) \\
& \mathrm{P}_{5}^{\prime}(\mathrm{t})=-\mu_{3} \mathrm{P}_{5}(\mathrm{t}) \\
& \mathrm{P}_{5}(0, \mathrm{t})=-\left(\mathrm{p} \lambda_{1}+\lambda_{3}\right) \mathrm{P}_{1}(\mathrm{t})+\left(\lambda_{1}+\lambda_{2}\right) \mathrm{P}_{3}(\mathrm{t})+\lambda_{1} \mathrm{P}_{1}(\mathrm{t})
\end{aligned}
$$

Initial conditions

$$
P_{0}(0)=1, P_{i}(0)=; i=1,2,3,4
$$

\section{Numerical computation and results:}

We get the following system of differential equations:

$$
\left[\mathrm{P}_{0}^{\prime}(\mathrm{t}) \mathrm{P}_{1}^{\prime}(\mathrm{t}) \ldots \ldots \ldots \ldots \ldots . . . . . \mathrm{P}_{5}^{\prime}(\mathrm{t})\right]^{\mathrm{T}}=\mathrm{A}\left[\mathrm{P}_{0}(\mathrm{t}) \mathrm{P}_{1}(\mathrm{t}) \ldots \ldots \ldots \ldots . . . \mathrm{P}_{5}(\mathrm{t})\right]^{\mathrm{T}}
$$

Where, $\mathrm{A}=$

$$
\left[\begin{array}{cccccc}
-\left(\lambda_{1}+\lambda_{2}\right) & \mu_{1} & \mu_{2} & 0 & 0 & \mu_{3} \\
\left(p \lambda_{1}+\lambda_{2}\right) & -\left(\lambda_{1}+\lambda_{2}+\mu_{1}\right) & \lambda_{3} & \mu_{2} & 0 & 0 \\
q \lambda_{1} & 0 & -\left(\lambda_{3}+\lambda_{2}+\mu_{2}\right) & 0 & 0 & 0 \\
0 & q \lambda_{1} & p \lambda_{1} & -\left(\lambda_{1}+\lambda_{3}+\mu_{2}\right) & \lambda_{2} & 0 \\
0 & 0 & q \lambda_{1} & 0 & -\left(\lambda_{1}+\lambda_{3}\right) & 0 \\
0 & 0 & 0 & 0 & 0 & -\mu_{3}
\end{array}\right]
$$

Initial conditions are as given below:

$$
\left[P_{0}(0) P_{1} \ldots \ldots \ldots \ldots \ldots \ldots P_{5}(0)\right]^{T}=[10 \ldots \ldots \ldots \ldots . .0]^{T}
$$

All computations have been carried out with following values of parameters:

$$
\begin{array}{ccc}
\lambda_{1}=.04 & \lambda_{2}=.001 & \lambda_{3}=.01 \\
\mu_{1}=.01 & \mu_{2}=.015 & \mu_{3}=.025 \\
\mathrm{p}=0.5 & \mathrm{q}=0.5 &
\end{array}
$$

Solving the above system of equations by Euler's modified method with step size $t=5$, as in (2) we obtain the state probabilities for all the states of the system. Table 1 presents these state probabilities alongwith system availability for a range of values for $t=0(10) 100$ where availability is given by

$$
\mathrm{A}(\mathrm{t})=\sum_{\mathrm{i}=0}^{4}(\mathrm{t})
$$

\section{Conclusion:}

It can be observed form the graph given in fig-2 that initially, system oscillates in states $S_{0}, S_{1}$ and $S_{2}$ for quit some time. These graphs start decreasing after that and graphs for state $S_{3}$ and $S_{4}$ start steadily increasing. The graphs of the failed state $\mathrm{S}_{5}$ starts increasing after some time of start and continues to increase. Its increment is sharp in the beginning and becomes steady at a later stage. The study of the behaviour of the state probabilities of the system may be quite useful in system design. The overall availability curve decreases with increase in time. 
Table-1

\begin{tabular}{|c|c|c|c|c|c|c|c|}
\hline \multicolumn{7}{|c|}{ System state probabilities \& availability } \\
\hline Time & State 0 & State 1 & State 2 & State 3 & State 4 & State 5 & A (t) \\
\hline 0 & 1 & 0 & 0 & 0 & 0 & 0 & 1 \\
\hline 10 & 0.6448 & 0.1667 & 0.1471 & 0.0205 & 0.0100 & 0.0110 & 0.9889 \\
\hline 20 & 0.4506 & 0.2172 & 0.1638 & 0.0684 & 0.03302 & 0.0669 & 0.9331 \\
\hline 30 & 0.3458 & 0.2208 & 0.1440 & 0.0978 & 0.0464 & 0.1450 & 0.8549 \\
\hline 40 & 0.2939 & 0.2079 & 0.1205 & 0.1079 & 0.0501 & 0.2195 & 0.7804 \\
\hline 50 & 0.2727 & 0.1921 & 0.1028 & 0.1066 & 0.0483 & 0.2776 & 0.7224 \\
\hline 60 & 0.2676 & 0.1785 & 0.0921 & 0.1006 & 0.0445 & 0.3166 & 0.6834 \\
\hline 70 & 0.2698 & 0.1689 & 0.0869 & 0.0939 & 0.0409 & 0.3396 & 0.6604 \\
\hline 80 & 0.2742 & 0.1630 & 0.0849 & 0.0885 & 0.03801 & 0.3512 & 0.6488 \\
\hline 90 & 0.2784 & 0.1598 & 0.0848 & 0.0848 & 0.0362 & 0.3559 & 0.6441 \\
\hline 100 & 0.2816 & 0.1583 & 0.0855 & 0.0826 & 0.0353 & 0.3567 & 0.6432 \\
\hline
\end{tabular}

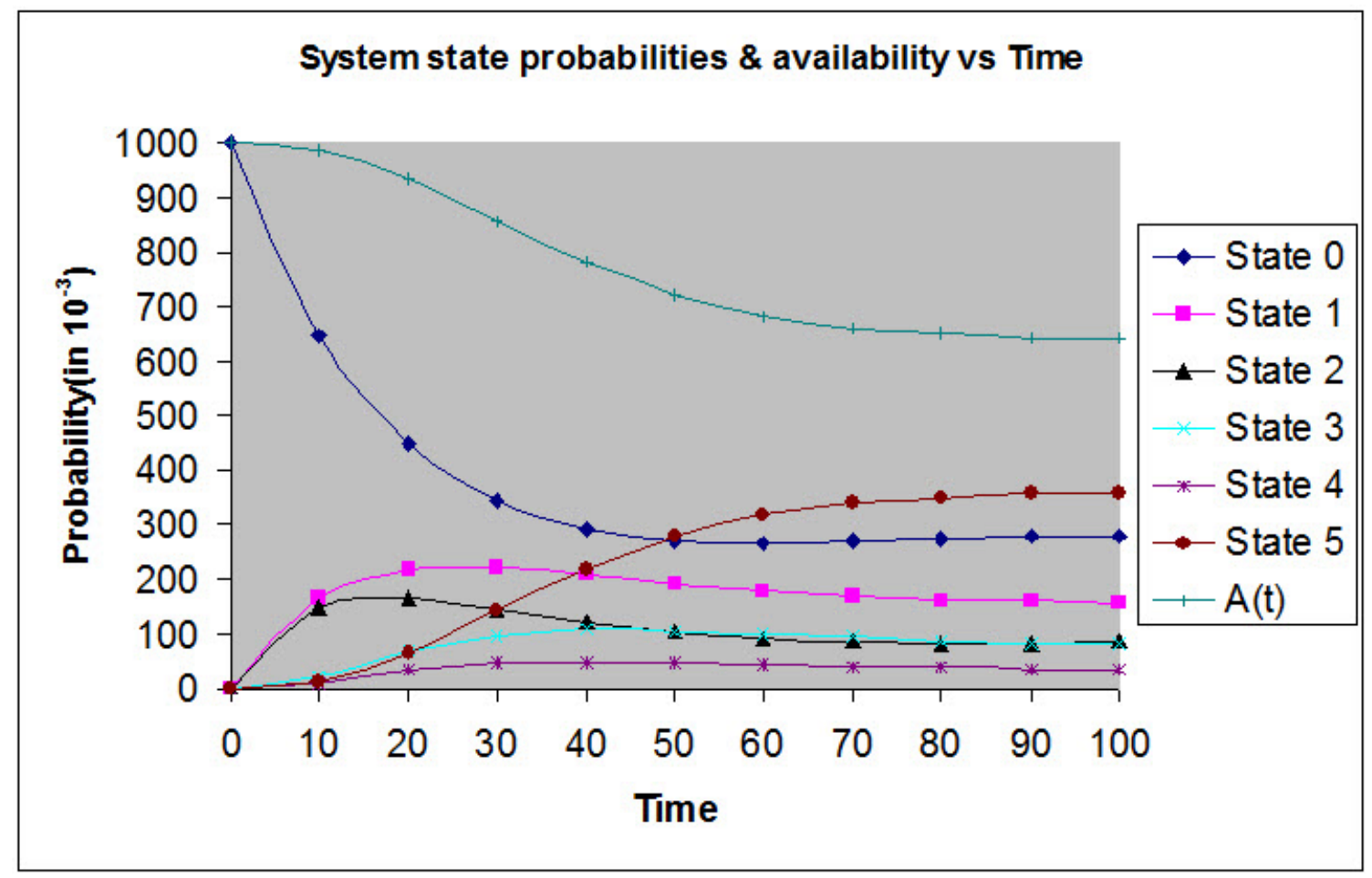

Figure-2

\section{Reference:}

[1] Mokaddis, G.S. and Towfek, M.L., "Some characteristic of a two- Dissimilar-unit cold standby redundant system with three modes." Vol.36 No.4,(1996) pp 497-503

[2] Pandey, D. and Jacob, Mendus., "Cost analysis, availability curve MTTF of a three state standby complex system under common cause and human failures.” Microlectron. Reliab. Vol. 35, No. 1, (1995), 91-95.

[3] Sur, B.N. and Sarkar T., "Numerical method of reliability evaluation Of a standby redundant system.” Microelectron. Reliab. Vol. 36 No. (1996), 693-696.

[4] Agnihotri, R.R.; Satsangi, S. K.: "Two Non-identical Unit System with Priority Based Repair and Inspection", Microelectronic Reliab. Vol. 36 (2), pp $279-282,1996$.

[5] Cassady, C.R.; Lyoob, I.M.; Schneider, K.; Pohi, E. A.: "A Generic Model of Equipment Availability under Imperfect Maintenance", IEEE TR on Reliability, Vol.54, issue - 4, pp 564 - 571, 2005

[6] Chung, W.K. : 'A k-out-of-N:G redundant system with the presence of chance with multiple critical errors', Microelectron. Reliab. Vol 33, pp334 (1993).

[7] Bansal K.K.,Sharma M.K.: A Comparative Study of Reliability Analysis of a Non-Series Parallel Network. International Journal of Education and Science Research Review Vol.2 (2015) 
[8] Sharma M.K. Bansal K.K: Fuzzy Analysis of Shortest Job First. International Journal of Engineering Research \& Management Technology Vol.2(3)(2015)

[9] Sharma M.K. Bansal K.K.: A Comparative Study of Reliability Analysis of a Non-Series Parallel Network. International Journal of Education and Science Research Review Vol.2(6)(2015)

[10] Dhillon, B.S Vishvanath, H.C. : 'Reliability analysis of non-identical unit parallel systems with common cause failure’, Microelectron Reliab. Vol. 31, pp 429-441 (1991).

[11] Gupta P.P. ; Kumar, A.; Mittal, S.K. : 'Stochastic behaviour of a three state complex repairable system with three types of failures', Microelectron. Reliab. 25, pp 853-858 (1985).

[12] Gupta P.P.,; Sharma, R.K. : ‘Cost analysis of three-state standby redundant electronic equipment’, Microelectron. Reliab. 25, pp 10291033 (1985).

[13] Kuo, W; Prasad, V.R.; Tillman, F.A. and Hwang, C.L: "Fundamental and Applications of Reliability Optimization”, Cambridge University Press, Cambridge, 2000.

[14] N.Ravichandran ; "Stochastic Methods in Reliability Theory", Wiley Eastern Ltd.; New Delhi, 1990.

[15] Nikolaidis, E.; Ghiocel , D.M. ; Singhal , S. : "Engineering Design Reliability Handbook", CRC Press, 2004.

[16] Rao, S.; Parulekar, B.B.: "Energy Technology”, Khanna Publishers, New Delhi, 2002.

[17] Tian, Z., Yam, R.C.M., Zuo, M.J., Huang, H.Z.: "Reliability bounds for multi-state k-out-of-n system”, IEEE TR. on Reliability, Vol.57 (1), PP 53-58, 2008.

[18] Zhao, X.; Cui, L.; Kuo, W.: "Reliability for Sparsely Connected Consecutive-k Systems”, IEEE TR. on Reliability, Vol.56, issue3, PP 516-524(2007). 